\title{
Recent applications of gem-dichloroepoxide intermediates in synthesis
}

\author{
Timothy S. Snowden* \\ Department of Chemistry, The University of Alabama, \\ Box 870336, Tuscaloosa, AL, USA 35487-0336 \\ E-mail: snowden@bama.ua.edu
}

\section{Dedicated to Professor Anthony J. Arduengo, III on the occasion of his $60^{\text {th }}$ birthday}

\begin{abstract}
This review highlights recent synthetic applications of the Jocic-Reeve, Corey-Link, and Bargellini reactions, all of which proceed through reactive gem-dichloroepoxide intermediates. Research published between 2001-early 2011 involving enhancements to the named reactions, new synthetic methods, target-directed synthesis, and drug discovery and development is emphasized.
\end{abstract}

Keywords: Dichloroepoxide, dichlorooxirane, Jocic, Reeve, Corey-Link, Bargellini, trichloromethyl carbinol

\section{Table of Contents}

1. Introduction

2. Jocic (Jocic-Reeve) Reactions

3. Corey-Link and Modified Corey-Link Reactions

4. Bargellini Reactions

5. Conclusion

6. Acknowledgements

7. References

\section{Introduction}

Dichloroepoxides are intermediates common to several named reactions including the Jocic (Jocic-Reeve), ${ }^{1}$ Corey-Link, ${ }^{2}$ and Bargellini ${ }^{3}$ reactions. In all three cases, 2-substituted 
carboxylic acids or acid derivatives are produced. The named reactions are differentiated by the substrates involved, subtle variances in mechanism, or the products obtained. Coincidentally, all three methods appear to have become "named reactions" through third party classification of each reaction by its respective discoverer(s) in separate 1998 publications. ${ }^{4}$ In the Jocic-Reeve and Corey-Link reactions, the intermediate gem-dichloroepoxides are formed in situ by treatment of readily accessible trichloromethyl carbinols (2) with base in protic or mixed media (Scheme 1). Nucleophiles readily undergo regioselective substitution at the $\alpha$-carbon (non-chloride bearing position) of the oxiranes (4) leading to formation of $\alpha$-substituted acid chlorides (5). The acid chlorides are subject to nucleophilic acyl substitution, including solvolysis, affording a variety of possible carboxylic acid derivatives (6) or heterocycles depending upon the reaction conditions used. Product yields are typically high, although alternative reaction paths are known to compete upon slight modifications of reaction conditions. ${ }^{5}$

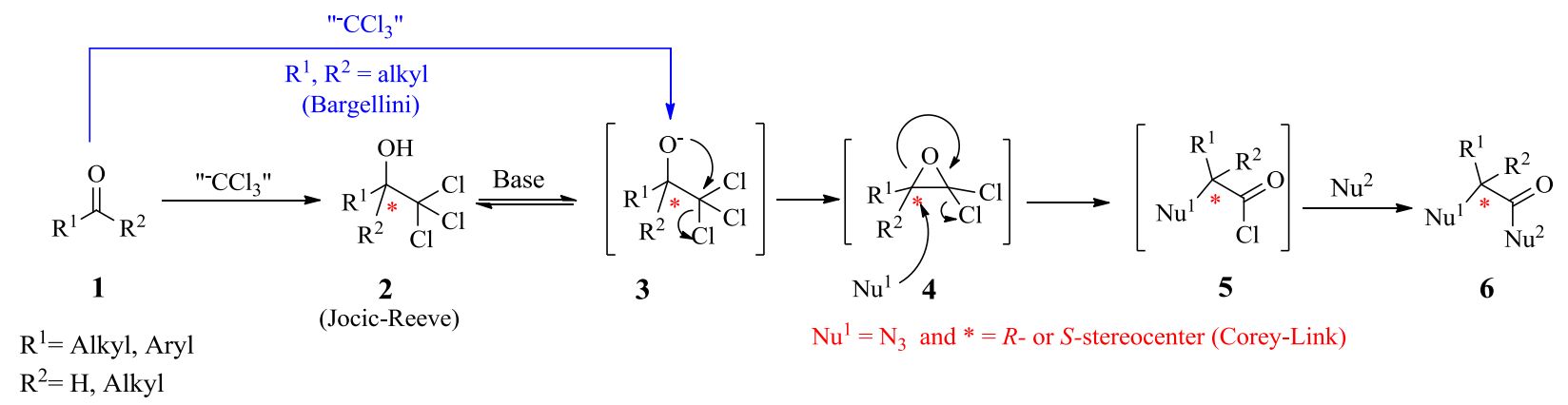

Scheme 1. General mechanism of reactions involving gem-dichloroepoxides (4).

The Corey-Link reaction is a specific example of the much broader and more general JocicReeve reaction. In the Corey-Link approach, asymmetric trichloromethyl carbinols are treated with azide to from chiral $\alpha$-azido carboxylic acid derivatives. ${ }^{2}$ These products are often subsequently reduced to furnish unnatural $\alpha$-amino acids in high yields. The Corey-Link reaction is arguably the most popular and recognizable of the reactions involving gem-dichloroepoxide intermediates.

Whereas Jocic-Reeve and commonly, although not exclusively, Corey-Link reactions begin by treating secondary trichloromethyl carbinols $\left(2\right.$ where $\mathrm{R}^{1}$ or $\left.\mathrm{R}^{2}=\mathrm{H}\right)$ with base, the Bargellini reaction typically involves addition of a sterically accessible ketone to trichloromethide (formed by deprotonation of added chloroform with hydroxide or DBU) resulting in an $\alpha$-trichloromethyl tertiary alkoxide (3). The alkoxide rapidly forms the gem-dichloroepoxide (4) without necessitating isolation of the carbinol 2 (Scheme 1). A key application of this reaction is the preparation of hindered $\alpha$-substituted carboxylic acid derivatives that may be difficult to prepare by direct nucleophilic substitution with congested 2-halocarboxylic acid derivatives.

The reaction sequence from intermediate 3 to product $\mathbf{6}$ highlighted in Scheme 1 is synthetically attractive for several reasons: 
- It involves a minimum of three discreet substitution reactions (intramolecular nucleophilic substitution to give reactive gem-dichloroepoxide intermediate 4 , inter- or intramolecular nucleophilic substitution and chloride elimination to produce 5, and nucleophilic acyl substitution to afford 6 ) in a one-pot process.

- The wide variety of heteroatom nucleophiles compatible with the necessary reaction conditions provides access to a broad range of $\alpha$-substituted carboxylic acid derivatives in a multi-component reaction process.

- The reactions are typically conducted in inexpensive aqueous or lower alcohol solvents (neat or with an organic co-solvent depending upon substrate solubility and nucleophile compatibility), and the by-products are $\mathrm{H}_{2} \mathrm{O}$ and $\mathrm{NaCl}$ under most conditions.

- The tolerance of protic media offers operational simplicity relative to typical epoxide substitution reactions.

- The gem-dichloroepoxide intermediates (4) are inherently reactive and do not require the addition of strong Lewis or Brönsted acids for substitutions to occur.

Disubstituted trichloromethyl carbinols ( 2 where $\mathrm{R}^{1}$ or $\mathrm{R}^{2}=\mathrm{H}$ ) used in Jocic-Reeve reactions are prepared in high yields by aldehyde additions to trichloromethide, from treatment of carbanions with chloral, or by reduction of trichloromethyl ketones, among other approaches. ${ }^{6}$ Due to the poor nucleophilicity of trichloromethide, from both steric and electronic perspectives, the preparation of many tertiary trichloromethyl carbinols $\left(2\right.$ where $\mathrm{R}^{1}$ and $\mathrm{R}^{2}=$ alkyl or aryl) by ketone additions to trichloromethide generally results in lower yields compared to additions by aldehydes. However, tertiary trichloromethyl carbinols more readily form gem-dichloroepoxides than their secondary counterparts (thereby allowing the Bargellini reaction to proceed without isolation of 2), and the resulting 2,2-disubstituted-1,1-dichloroepoxides (4 where $\mathrm{R} \neq \mathrm{H}$ ) are more stable and less prone to side reactions than the kinetically reactive 2-monosubstituted species $\left(4\right.$ where $\mathrm{R}^{1}$ or $\left.\mathrm{R}^{2}=\mathrm{H}\right){ }^{7}$ Synthetic applications involving gem-dichloroepoxide intermediates reported in publications during the past decade (2001-early 2011) are the focus of this review. More details related to each named reaction are supplied in each respective section.

\section{Jocic (Jocic-Reeve) Reactions}

The Jocic reaction, ${ }^{1}$ or preferably the Jocic-Reeve reaction considering Wilkins Reeves' seminal contributions to both the mechanistic understanding and development of applications of the original Jocic reaction, ${ }^{5,8,9}$ is a powerful method for the preparation of a variety of $\alpha$-substituted carboxylic acid derivatives and heterocycles. The reaction proceeds through a gemdichloroepoxide intermediate and was first disclosed by Zicojin Jocic in 1897. He reported a preparation of 2,2,2-trichloro-1-phenylethanol and its unexpected conversion to 2-chloro-2phenylacetic acid in $22 \%$ yield upon treatment with aqueous $\mathrm{KOH} .{ }^{1}$ Jocic's publication appeared nine years prior to Bargellini's, ${ }^{3 \mathrm{~b}}$ which also involved preparation of a product proceeding 
through a gem-dichloroepoxide intermediate. However, Link disclosed a Bargellini-type reaction in an 1894 patent application, and hence, might have been the first to report a method involving a gem-dichloroepoxide. ${ }^{3 a}$ Wilkins Reeve conducted extensive mechanistic investigations on the original reaction reported by Jocic as well as new conversions of trichloromethyl carbinols into 2-substituted carboxylic acids and heterocycles between 1960-1980. ${ }^{5,8,9}$ Although Corey and Link are duly credited with the preparation of $\alpha$-amino acids from trichloromethyl carbinols (the Corey-Link reaction, vide infra), Reeve appears to be the first to prepare $\alpha$-amino acids in a Jocic-type process, although his syntheses were racemic. ${ }^{9}$ Researchers have expanded JocicReeve reactions considerably in scope and breadth since Reeve's pioneering investigations. Advances and applications since 2001 are the focus of this section.

In 2004, Blanchet and Zhu reported the preparation of several substituted 2-imino-4thiazolidinones (10) by way of the Jocic-Reeve reaction (Scheme 2). ${ }^{10}$ The authors significantly improved upon Reeve's reported yield for the synthesis of 2-imino-5-phenylthiazolidin-4-one ${ }^{8 \mathrm{~d}}$ after conducting an extensive survey of bases and solvents. Optimal conditions required treatment of 2,2,2-trichloro-1-phenylethanol with thiourea using four equivalents of $\mathrm{NaOH}$ in DME- $\mathrm{H}_{2} \mathrm{O}$. The secondary trichloromethyl carbinols (unlike tertiary trichloromethyl carbinols, vide supra) did not react appreciably when treated with DBU in methyl alcohol or when introduced to base in aprotic media. The authors also established a one-pot conversion of aldehydes to 10, albeit in lower yields relative to the two-step approach.

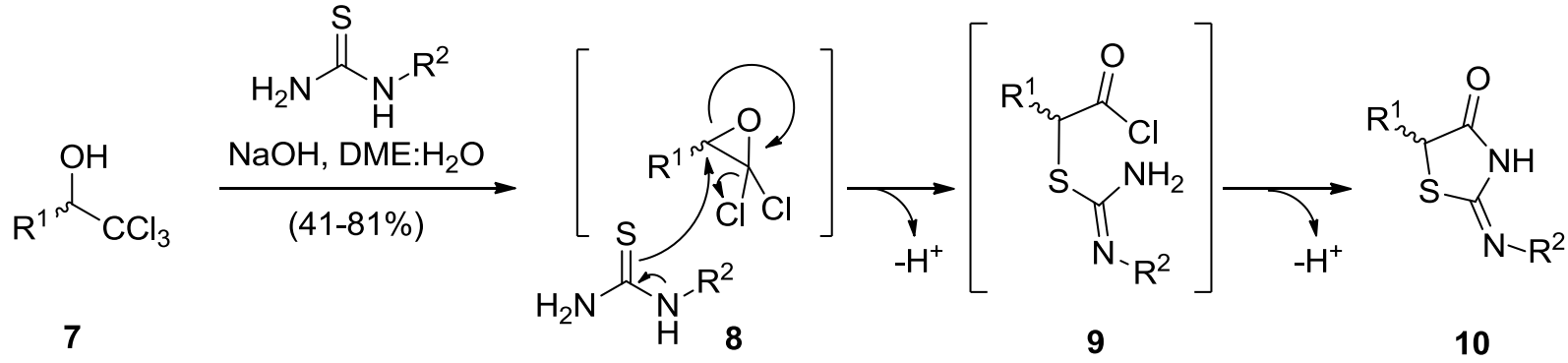

$\mathrm{R}^{1}=$ aliphatic, Cy, allyl, aryl

$\mathrm{R}^{2}=\mathrm{H}, \mathrm{Ph}, 4-\mathrm{BrPh}$

Scheme 2. Preparation of 2-imino-4-thiazolidinones (10) by a Jocic-Reeve reaction.

Stick and coworkers surveyed the reactions of five nucleophiles with trichloromethyl- $\alpha$-Dallofuranose derivative 11 in methyl alcohol using DBU, rather than hydroxide, as the base. ${ }^{11}$ These modified Jocic-Reeve reaction conditions, analogous to those introduced by Dominguez in the so-called modified Corey-Link reaction, ${ }^{4 \mathrm{~b}}$ produced several interesting $\alpha$-substituted methyl esters 12 in moderate to high yields (Table 1). Notably, fluoride product 12b was prepared in high yield using CsF as a nucleophile source. Such conditions proved superior to those employed by Oliver and coworkers in their earlier preparations of $\alpha$-fluorocarboxylic acids by Jocic-Reeve reactions, ${ }^{12}$ although Oliver surveyed less compliant disubstituted trichloromethyl carbinols 
rather than 11, which proceeds through an uncharacteristically isolable gem-dichloroepoxide intermediate during the generation of $\mathbf{1 2}$.

Table 1. Modified Jocic-Reeve reaction of $\mathbf{1 1}$ with various nucleophiles

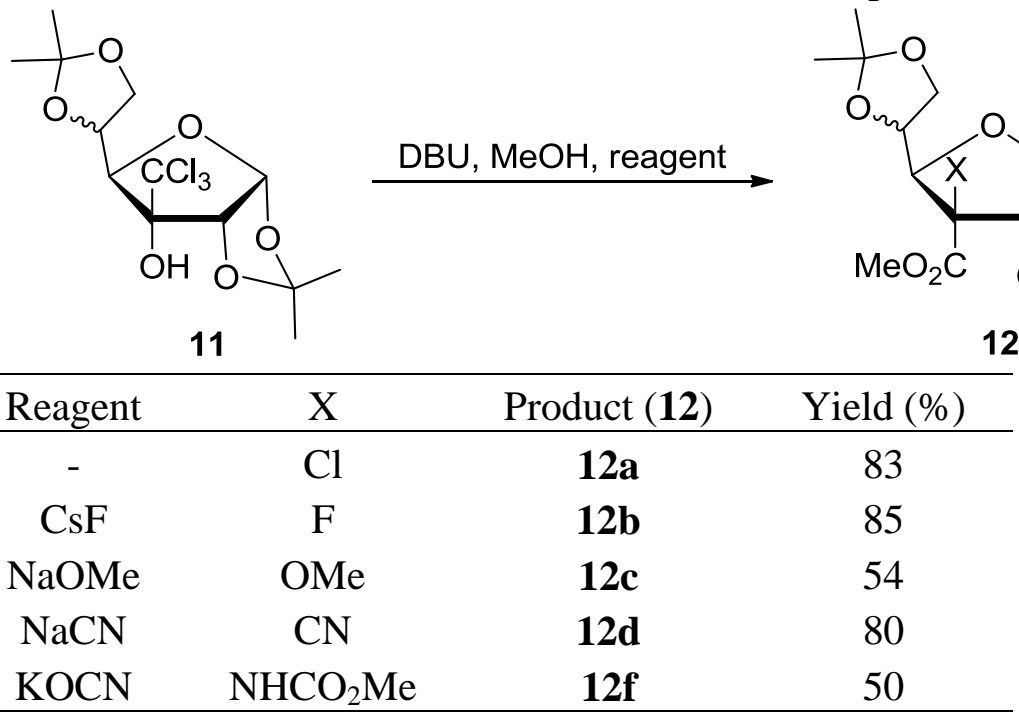

Matsunaga, Shibasaki, and coworkers described a highly diastereoselective synthesis of $\alpha-$ substituted- $\beta$-aminotrichloromethyl ketones via a Mannich-type reaction. ${ }^{13}$ The $\beta$-amino ketones were readily reduced to syn- or anti-aminotrichloromethyl alcohols (13) and then treated with sodium hydroxide in DME: $\mathrm{H}_{2} \mathrm{O}$ to afford substituted azetidine-2-carboxylic acids (e.g., 15) (Scheme 3). Both cis- and trans-carboxylic acid epimers of 15 were accessible from the corresponding anti-1,3- or syn-1,3-aminoalcohol diastereomers, respectively. The resulting acids were $O$-methylated prior to isolation to afford readily handled methyl esters. The combined yields for the Jocic-Reeve reactions and subsequent methylations ranged from $57-72 \%$.

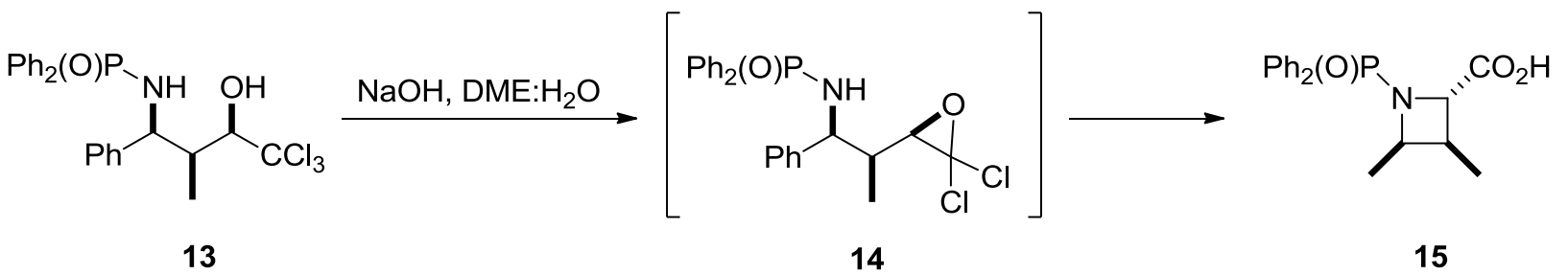

Scheme 3. Diastereoselective synthesis of substituted azetidine-2-carboxylic acids by an intramolecular Jocic-Reeve reaction.

During the past several years, our group has had an interest in extending the scope of the Jocic-Reeve reaction. Our first investigation concerned the regioselective substitution of alkenyl gem-dichloroepoxides derived from allylic trichloromethyl carbinols using various nucleophiles. ${ }^{14}$ In that study, and in reactions since, we found that reagents which are poorly nucleophilic in protic media, such as hydroxide, preferentially undergo $S_{N} 2$ ' reactions with the 
intermediates (17) to give $\gamma$-substituted enoic acids 19 (Scheme 4). However, nucleophiles that are modest hydrogen bond acceptors, including thiolates, selenides, and azide, strongly prefer an $\mathrm{S}_{\mathrm{N}} 2$ pathway to furnish 18. Some nucleophiles, including alkoxides, amines, and borohydrides, generally offer poor regioselectivity.

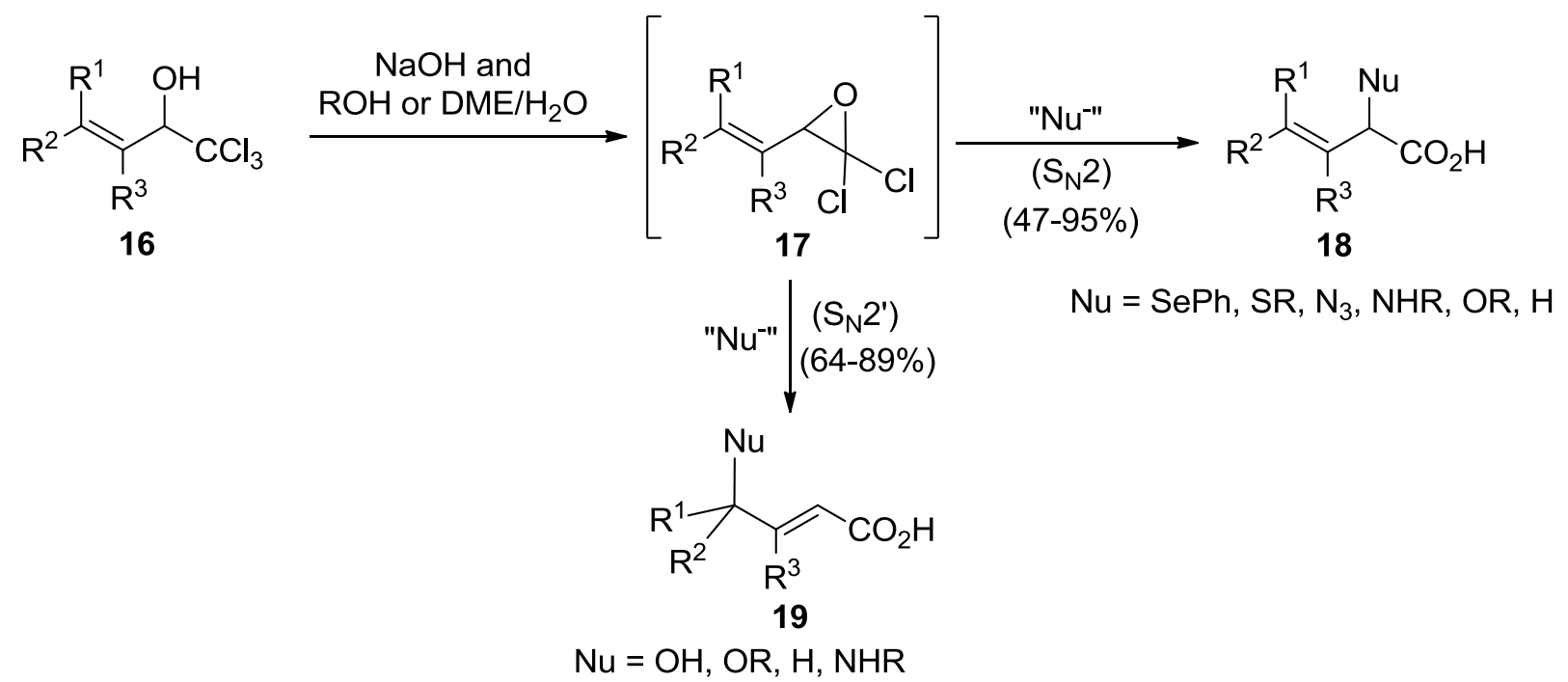

Scheme 4. Investigation of regioselective substitution involving alkenyl gem-dichloroepoxides (17).

We have also exploited the reactivity of gem-dichloroepoxide intermediates in the development of convenient and inexpensive one-carbon homologation-functionalization reactions. The conversion of aldehydes (20) to trichloromethyl carbinols (7) followed by treatment with $\mathrm{NaBH}_{4}$ in alkaline tert-butyl alcohol or with sodium phenylseleno(triethyl)borate complex, prepared in situ, in ethyl alcohol ${ }^{15}$ affords high yields of homologated carboxylic acids 21 (Scheme 5). ${ }^{16}$ The approach is amenable to homologation-functionalization of (hetero)aryl, alkyl, and alkenyl aldehydes, and even sensitive enolizable aldehydes with $\alpha$-stereocenters. We have recently developed a modified Jocic-Reeve reaction that affords homologated primary, secondary, or tertiary amides, including Weinreb amides, in high yields under similar conditions. ${ }^{17}$ We have also devised the first one-pot preparation of trichloromethyl carbinols from primary alcohols. ${ }^{18}$ Thus, one-carbon homologated acids or amides can now be formed from most primary alcohols or aldehydes in just two operational steps.

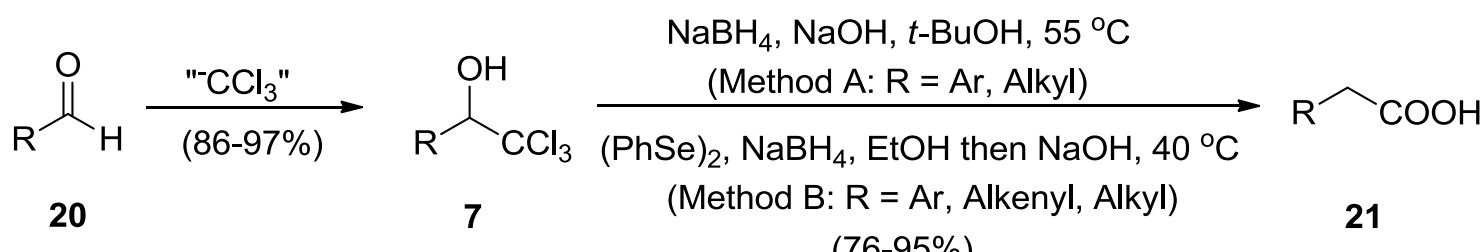

(76-95\%)

Scheme 5. Two-step homologation-functionalization of aldehydes. 


\section{Corey-Link and Modified Corey-Link Reactions}

E. J. Corey and John Link published research that evolved and popularized the Jocic-Reeve reaction. In 1992, the authors reported a convenient and mild method of preparing racemic trichloromethyl carbinols from aldehydes under effectively neutral conditions, ${ }^{2 \mathrm{a}}$ they published the first enantioselective approach to trichloromethyl carbinols by way of chiral oxazaborolidine reductions of trichloromethyl ketones, ${ }^{2 b}$ and they provided a route to artificial chiral $\alpha$-amino acids that rivals the most popular and versatile approaches of the past two decades. ${ }^{2 \mathrm{c}}$ The extension of the Jocic-Reeve reaction to the asymmetric synthesis of $\alpha$-azido acids is commonly referred to as the Corey-Link reaction. ${ }^{4 \mathrm{~b}}$ It is important to note that stereochemical integrity of the intermediate $\alpha$-substituted acid chloride (5) is typically preserved in these reactions (clean inversion of configuration in $\mathbf{4}$ and little or no ketene formation/racemization thereafter) despite the use of $\mathrm{KOH}$ in $\mathrm{DME} / \mathrm{H}_{2} \mathrm{O}$ or other protic media.

Dominguez and coworkers reported a modification of the Corey-Link reaction wherein hydroxide is substituted with $\mathrm{DBU}$ in a lower alcohol (for example, $\mathrm{MeOH}$ or EtOH) for the generation of the gem-dichloroepoxide, and $\mathrm{NaN}_{3}$ and catalytic 18-crown-6 are included for the azidation step. ${ }^{4 \mathrm{~b}}$ Under these milder, anhydrous conditions, $\alpha$-azidoesters are formed rather than the acids created by the original Corey-Link approach. The Dominguez "modified Corey-Link reaction", as it is commonly tagged, has largely supplanted the original 1992 protocol. The method has been successfully applied to the synthesis of disparate targets throughout the first decade of the new millennium as highlighted in this section.

In 2001, Aitken and coworkers compared the yields and enantiomeric excesses arising from the conversion of $(R)$-2,2,2-trichloro-1-phenylethanol into $(S)$-2-phenylglycine by the CoreyLink approach. ${ }^{19}$ The authors established that the highest yields were obtained when four equivalents of $\mathrm{NaOH}$ or more than one equivalent of $\mathrm{DBU}$ was used. However, significant racemization was noted when hydroxide bases were employed, whereas the product was obtained in $>90 \%$ e.e. when substrates were treated with slightly more than one equivalent of DBU. It is important to note that racemization when using hydroxide is not a general drawback the Corey-Link reaction, but rather, it appears to be restricted to select $\alpha$-azido products or reaction intermediates.

Romo and coworkers have developed a number of elegant synthetic methods starting from $\beta$ lactones, including chiral Wynberg lactone (22). ${ }^{20}$ The masked chiral trichloromethyl carbinol in readily accessible $(\boldsymbol{R})$ - or $(\boldsymbol{S})-\mathbf{2 2}$ is revealed by hydride reduction or other common nucleophilic acyl substitution reactions. Subsequent treatment in a Jocic-Reeve or Corey-Link reaction affords products with expanded complexity in a minimal number of operations. In 2002, the Romo group reported a two-step preparation of $(S)-26$ from $(\boldsymbol{R})$-22 by way of a hydride reduction, Corey-Link reaction, intramolecular $O$-acylation sequence followed by an optimized lactone workup procedure (Scheme 6). ${ }^{20 \mathrm{~b}}$ Chiral GC analysis indicated that the product contained only $\sim 2.5 \%$ racemized $\alpha$-azidolactone $(\boldsymbol{R})$-26. Romo also highlighted an approach to natural amino acid 28 
beginning from $(\boldsymbol{R})-\mathbf{2 2}$. The sequence featured the Corey-Link amino acid synthesis with a Staudinger reduction modification in the final step.

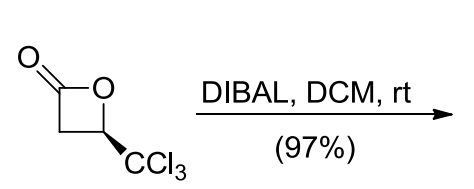

$(R)-22$

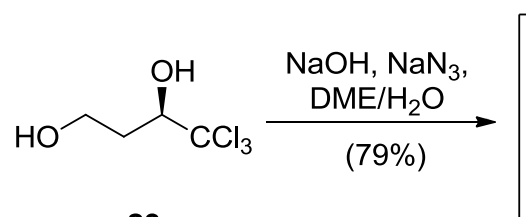

23

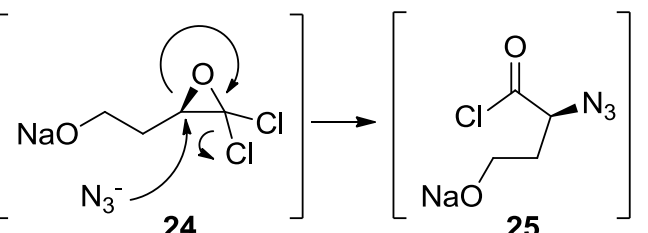

24

25

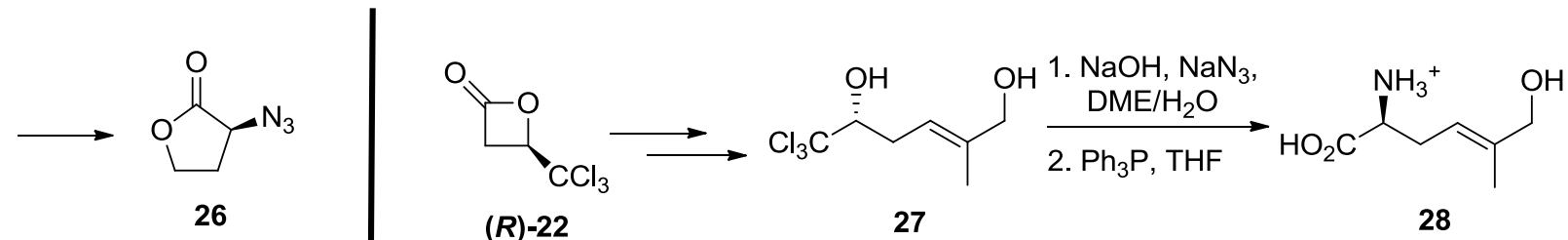

$(R)-22$

28

Scheme 6. Novel Corey-Link reactions beginning from Wynberg lactone(22).

Nielsen and coworkers prepared a bicyclic analog of the anti-HIV drug AZT by incorporating a modified Corey-Link reaction in a key step. ${ }^{21}$ Starting from D-arabinose, the researchers prepared trichloromethyl carbinol $\mathbf{2 9}$ from the corresponding ketone then transformed 29 into 30 in high yield and without epimerization (Scheme 7). Elaboration of 30 led to creation of nucleoside analog $\mathbf{3 1}$ and its $\alpha$-anomer.

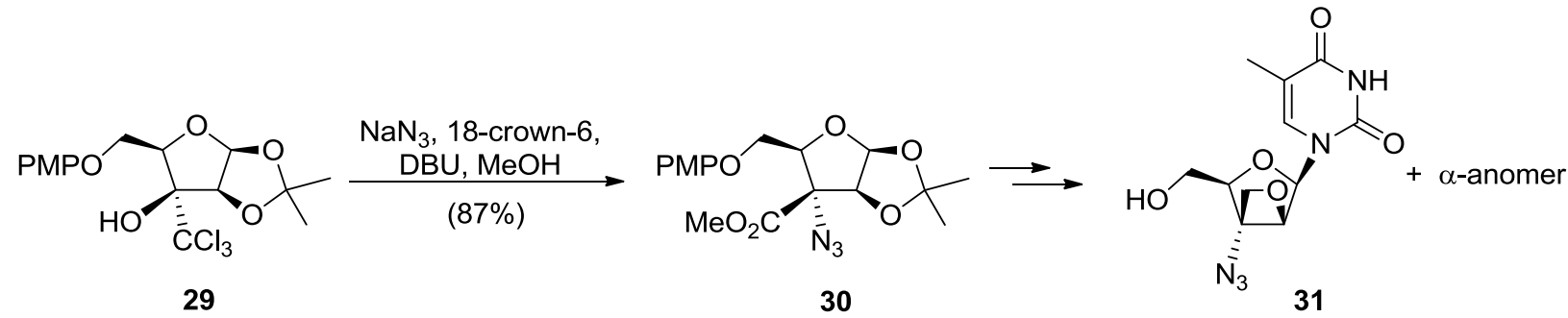

Scheme 7. Preparation of azido-nucleoside analogs via a modified Corey-Link reaction.

A useful approach to the synthesis of various carbohydrate $\alpha$-amino acids and esters was relayed by Stick and coworkers in two papers published in $2004 .^{22}$ Similar to Nielsen, et al., ${ }^{21}$ the researchers converted carbohydrate ketones into asymmetric trichloromethyl carbinols (e.g., 29) through substrate-controlled addition of lithium trichloromethide. The resultant trichloromethyl alcohols were subjected to modified Corey-Link conditions to obtain $\alpha$-azidoesters and acids, after ester hydrolysis, and $\alpha$-aminoesters, after azide reduction, in good yields and with high stereocontrol (Scheme 8). Several furanose and pyranose analogs were prepared along with azidonucleoside 36. The carbohydrate $\alpha$-amino acids were also subsequently coupled to furnish novel carbohydrate oligopeptides. ${ }^{23}$ 


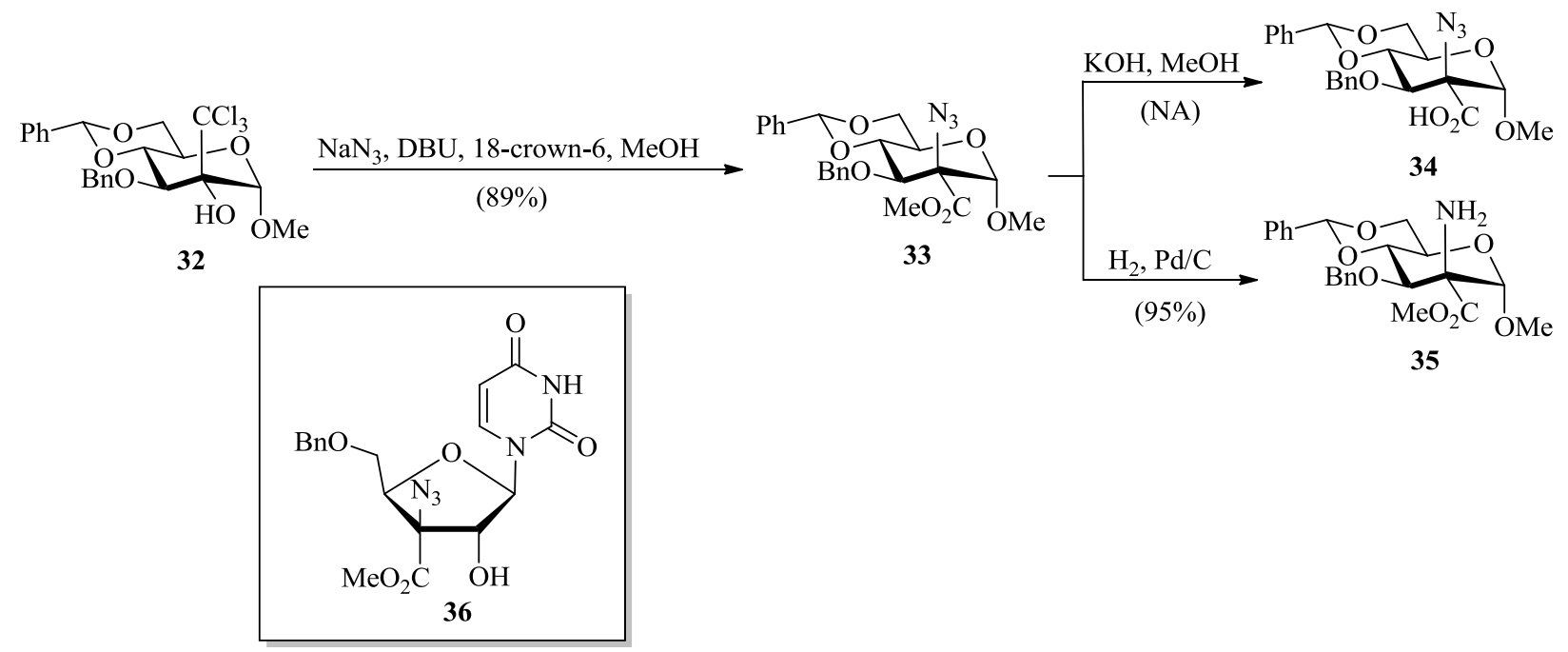

Scheme 8. Preparation of azido- and amino acid analogs of carbohydrates and of nucleoside 36.

Pedregal and Prowse at Eli Lilly \& Co. synthesized a racemic fluorinated analog (39) of metabotropic glutamate receptor agonist LY354740 by taking advantage of the stereoselective modified Corey-Link protocol. ${ }^{24}$ Attempts to prepare the amino acid functionality by way of Strecker or Bucherer-Berg reactions proved problematic. However, the modified Corey-Link reaction proceeded in $89 \%$ yield without epimerization and allowed for generation of targeted amino acid products (39) after azide reduction and ester hydrolysis (Scheme 9).

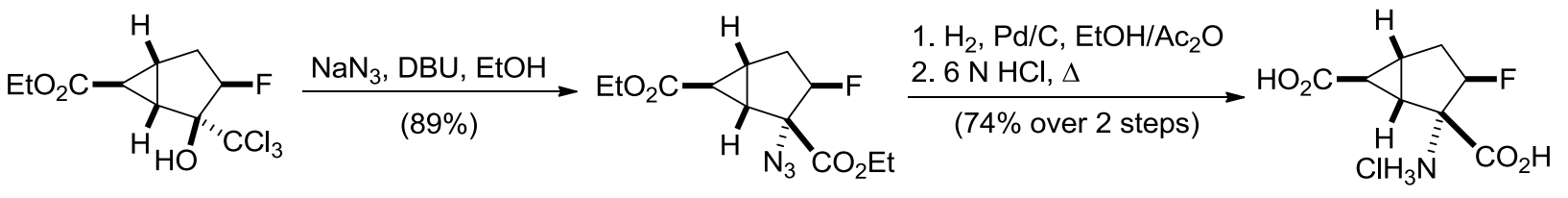
$( \pm)-37$ $( \pm)-38$

$( \pm)-39$

Scheme 9. Synthesis of fluorinated amino acid 39 involving a modified Corey-Link reaction.

Schafmeister and coworkers applied the modified Corey-Link and the original Corey-Link procedures in separate syntheses of precursors (41 and 43 ) en route to two cyclic bis-amino acid monomers (Scheme 10). ${ }^{25}$ It is notable that the benzyl ester in $\mathbf{4 2}$ was not saponified during the transformation to 43. Once prepared, the cyclic monomers 41 and 43 were employed to fashion spatially defined spiro-ladder oligomers for use as functionalized nanostructures in molecular recognition applications. 
<smiles>COC(=O)C1C[C@H]2CC[C@@](O)(C(F)(Cl)Cl)C[C@H]2N1C(=O)OCc1ccccc1</smiles>

$\mathrm{NaN}_{3}$, DBU, 18-crown-6, MeOH $(97 \%)$<smiles>CCCOC(=O)C[C@@H]1[C@H](C(=O)OCc2ccccc2)N(PC)C[C@]1(O)Cl</smiles>

42
$\mathrm{NaN}_{3}, \mathrm{NaOH}, \mathrm{H}_{2} \mathrm{O}$ :dioxane (1:1)

$(87 \%)$

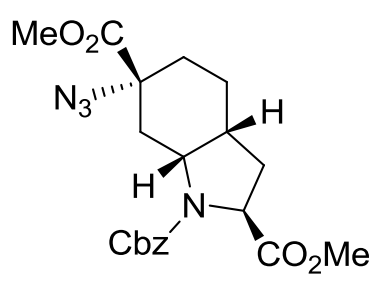

41

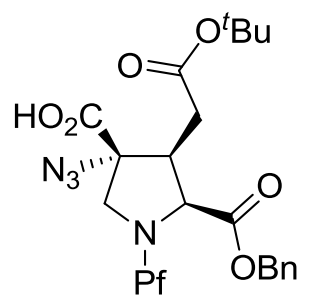

43

$\mathrm{Pf}=$ phenylfluorenyl

Scheme 10. Synthesis of $\alpha$-azidocarboxylic acid derivatives 41 and 43 by Corey-Link reactions.

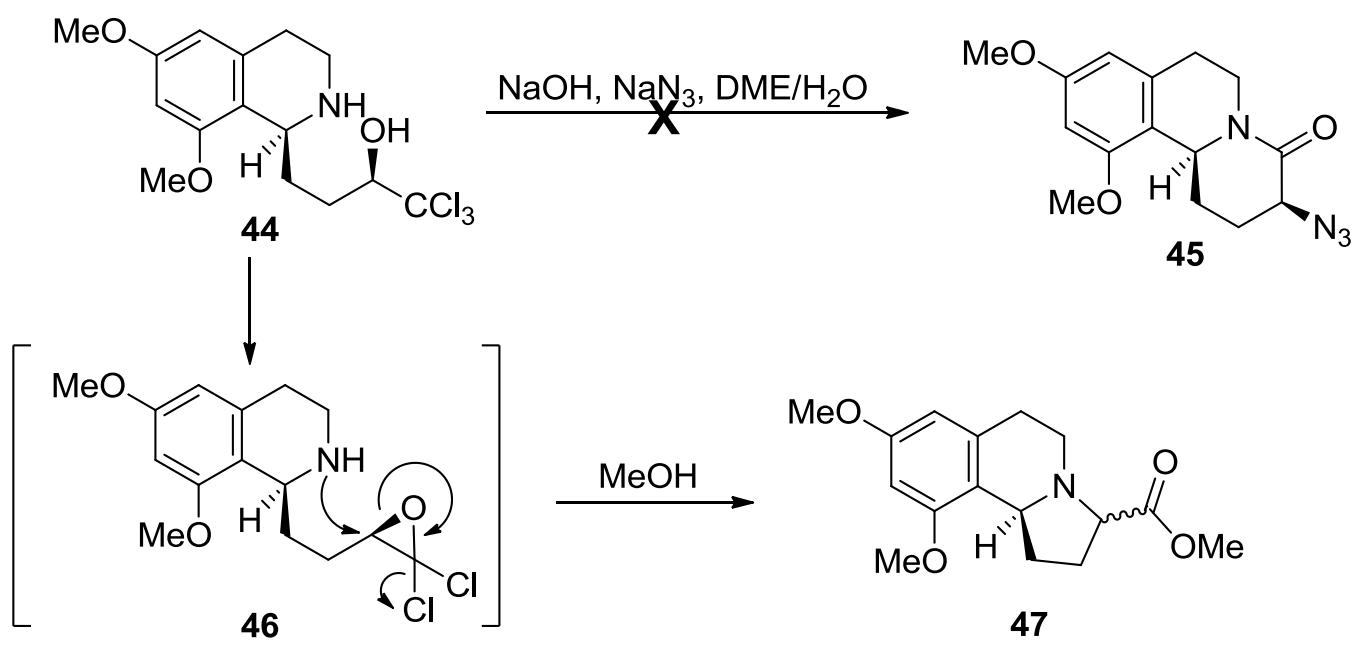<smiles>COc1cc2c(c(OC)c1)[C@H](CCC(O)C(Cl)(Cl)Cl)NCC2</smiles>

1. $(\mathrm{Boc})_{2} \mathrm{O}, \mathrm{DCM}$

2. $\mathrm{NaOH}, \mathrm{NaN}_{3}, \mathrm{DME} / \mathrm{H}_{2} \mathrm{O} \quad \mathrm{MeO}$

3. TFA, DCM, $0^{\circ} \mathrm{C}$

4. $\mathrm{Et}_{3} \mathrm{~N}, \mathrm{DPPA}, \mathrm{DMF}$<smiles>COc1cc(C)cc2c1[C@H]1CC[C@H](N)C(=O)N1CC2</smiles>

Scheme 11. Key steps to advanced intermediate 45 in Romo's syntheses of schulzeines B and C. 
Recently, Liu and Romo described their enantioselective synthesis of potent $\alpha$-glucosidase and viral neuraminidase inhibitors schulzeines B and C. ${ }^{26}$ A key step in the approach was a planned Corey-Link reaction/intramolecular amidation to fashion the $\alpha$-amino $\gamma$-lactam. However, initial treatment of 44 with $\mathrm{NaOH}$ and $\mathrm{NaN}_{3}$ in $\mathrm{DME} / \mathrm{H}_{2} \mathrm{O}$ afforded undesired intramolecular Jocic-Reeve reaction product $\mathbf{4 7}$ rather than the desired intermolecular azide substitution-intramolecular $N$-acylation target 45 (Scheme 11). Protection of the tetrahydroisoquinoline secondary amine followed by a Corey-Link reaction, amine deprotection, and lactamization using diphenylphosphoryl azide (DPPA) provided key intermediate 45 en route to successful attainment of the individual epimeric marine alkaloids.

\section{Bargellini Reactions}

The Bargellini reaction is a multicomponent coupling reaction that involves the treatment of in situ-generated trichloromethide with acetone or another sterically accessible ketone and a heteroatom nucleophile to form 2-heterosubstituted-2,2-dialkylcarboxylic acid (2heterosubstituted isobutyric acid) derivatives. ${ }^{3}$ The product is formed by way of regioselective addition to an intermediate gem-dichloroepoxide (Scheme 1). In general, alkyl aldehydes are not compatible with this reaction primarily due to competing aldol condensation and the relatively slow rate of dichloroepoxide formation from any formed secondary trichloromethyl alkoxide. ${ }^{7}$ However, when ketones are used, the protocol offers rapid, convenient, and cost effective access to 2-heterosubstituted-2,2-dialkylcarboxylic acid derivatives and heterocycles. Unlike research related to the Jocic-Reeve or Corey-Link reactions, many of the advances associated with Bargellini couplings have been reported by researchers in the pharmaceutical industry. Several manuscripts published during the past decade expanded the breadth of the reaction by highlighting alternative nucleophiles and ketones amenable to the reaction conditions. As a result, the Bargellini reaction now offers a one-pot, proven route to the preparation of a broad range of hindered carboxylic acids and acid derivatives. Applications and modifications reported since 2001 are highlighted in this section.

John Lai of BF Goodrich developed several extensions to, and revealed applications of, the Bargellini reaction during the past three decades. ${ }^{27}$ In 2001, he reported the use of a hindered, activated arene, 2,6-di-tert-butylphenol (48), as a carbon nucleophile in a clever one-pot Bargellini reaction to create a series of hindered 2,6-di-tert-butyl-4-(1,1-dialkyl-1acetamide)-

phenols 50 (Scheme 12). ${ }^{28}$ Many of the products afforded persistent phenoxy radicals with halflives appreciably longer than that of 2,4,6-tert-butylphenoxy radical. 


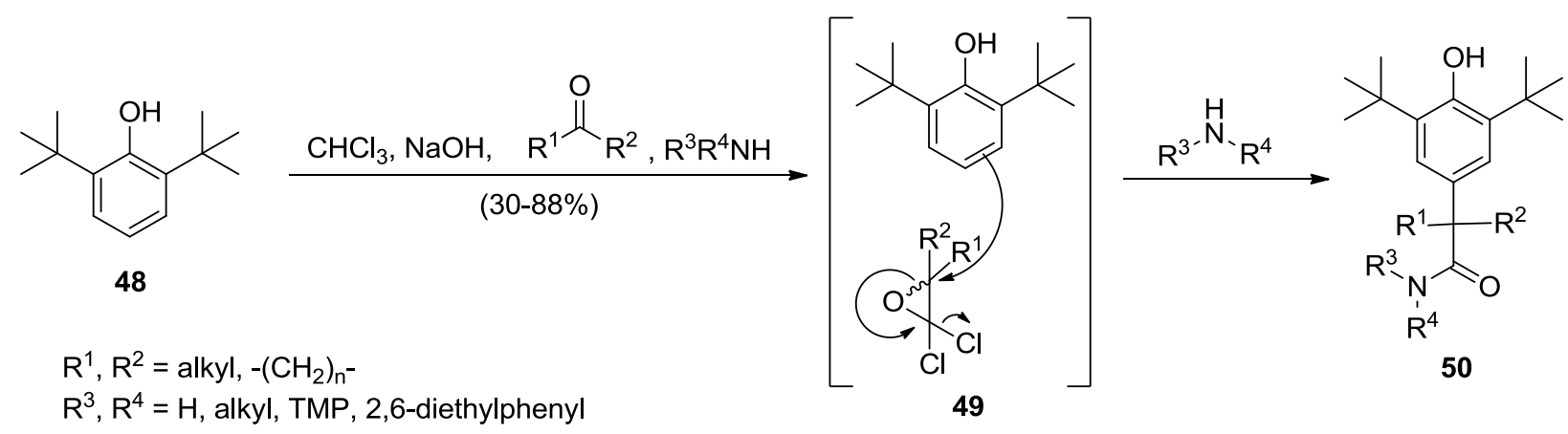

Scheme 12. Combination of Bargellini and Friedel-Crafts alkylation reactions to prepare phenoxy radical precursors $\mathbf{5 0 .}$

Abraham and coworkers applied a Bargellini reaction to a gram-scale synthesis of 52, a known allosteric effector of hemoglobin (Hb) (Scheme 13). ${ }^{29}$ Compound 52 served as a lead for amino acid conjugates expected to act as new allosteric modifiers of $\mathrm{Hb}$. Although a Bargellini protocol was initially adopted to prepare 52, the researchers ultimately performed $O$-alkylation reactions with ethyl-1-bromocyclopentane carboxylate for larger scale preparations of $\mathbf{5 2}$ en route to their series of amino acid conjugates.

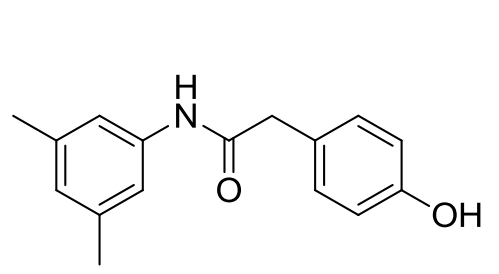

51

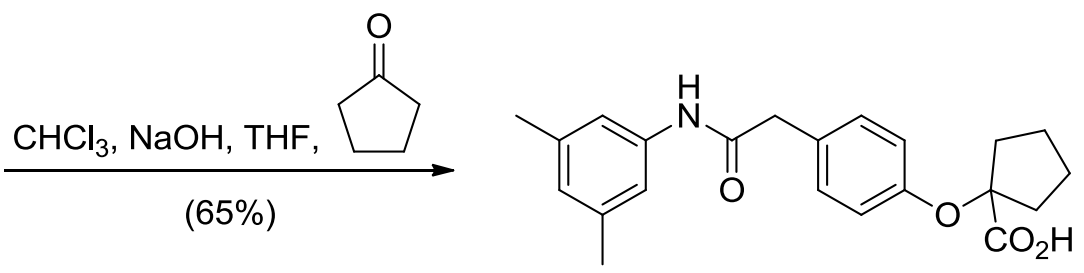

52

Scheme 13. Preparation of bioactive amino acid conjugate precursors 53 by a Bargellini reaction

In 2004, researchers at GlaxoSmithKline reported that use of 2-bromo-2-methylpropanoic acid under alkaline conditions afforded valuable 2-methyl-2-aryloxypropanoic acid derivatives on gram to multi-kilogram scales. ${ }^{30}$ They noted that employment of 2-bromo-2-methylpropanoic acid proved superior to other conditions, including those used in the Bargellini reaction, because 2-bromo-2-methylpropanoic acid lessens safety concerns associated with possible $\mathrm{CHCl}_{3}$ regeneration, mesityl oxide formation (from acetone), and the exothermicity associated with the introduction of 1,1,1-trichloro-2-methyl-2-propanol (chloretone) commonly employed in the Bargellini protocol. However, researchers at Merck thoroughly investigated several procedures for the preparation of dual PPAR $\alpha / \gamma$ agonist 54 and found the direct conversion of benzisoxazole 53 to target 54 by way of an optimized Bargellini reaction offered superior results in terms of yield and step economy (Scheme 14). ${ }^{31}$ Mesityl oxide formation and exothermicity were not problematic under the optimized conditions. During their investigation, the authors also established the half-life of the presumptive kinetically reactive 1,1-dichloro-2,2-dimethyloxirane 
in basic acetone as approximately five minutes based upon ReactIR studies. The oxirane intermediate could not be observed by NMR spectroscopy, presumably due to the consistently low concentration of the reactive dichloroepoxide throughout the course of the reaction. The Merck finding is consonant with our observations involving attempted detection of gemdichloroepoxide intermediates by NMR spectroscopy during several of our studies.<smiles>CCCc1cc2c(C(F)(F)F)noc2c(CCC)c1O</smiles>

53

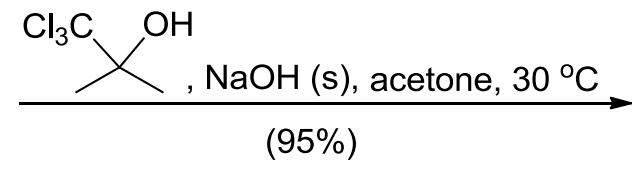

$(95 \%)$<smiles>CCCc1cc2c(C(F)(F)F)noc2c(CCC)c1OC(C)(C)C(=O)O</smiles>

54

Scheme 14. Optimized synthesis of dual PPAR $\alpha / \gamma$ agonist 54 exploiting a Bargellini reaction.

Venkateswaran and coworkers reported applications of the Bargellini reaction in the preparation of helianane 57 and several heliannuols (Scheme 15). ${ }^{32}$ Treatment of coumarins or dihydrocoumarins with chloroform and aqueous $\mathrm{NaOH}$ in acetone afforded diacids (56) in 65$75 \%$ yields. Elaboration of one of the diacid products afforded marine metabolite helianane (57) in five additional steps. Related efforts with other substituted coumarins furnished sunflower allelochemicals heliannuols C (58) and A (59) along with enantiomeric and epimeric stereoisomers.

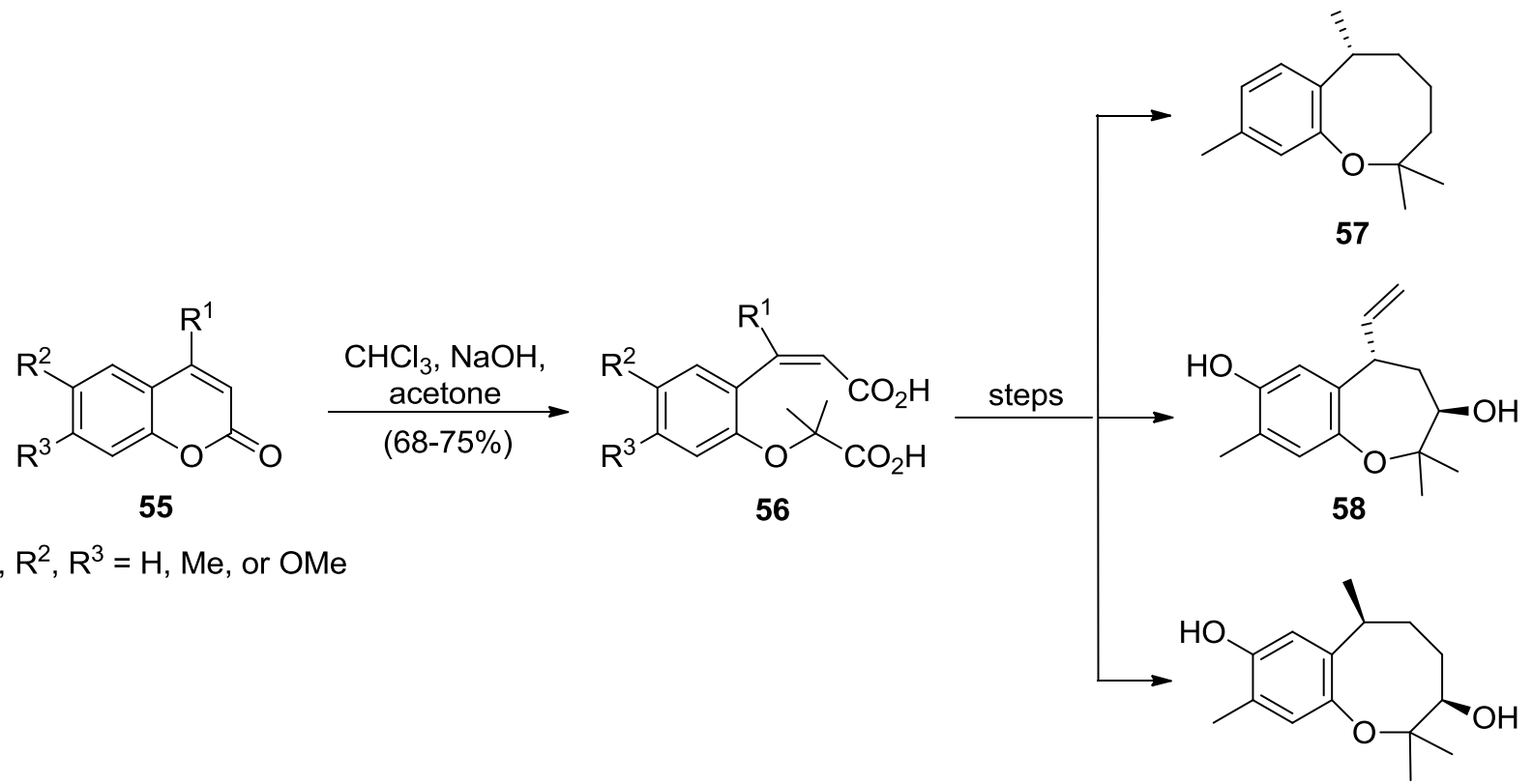

59

Scheme 15. Bargellini reactions in key early steps of conversions of coumarin derivatives to helianane (57) and stereoisomers of heliannuols C (58) and A (59). 
Butcher and Hurst showed that weakly nucleophilic anilines and amine-substituted heterocycles can be used in Bargellini reactions to prepare hindered $\alpha$-amino acid derivatives in a single step (Scheme 16). ${ }^{33}$ Product yields were highly dependent upon the amine nucleophile employed. However, the step-economy of the approach offers clear advantages over many other strategies as illustrated by the authors' comparative synthesis of a racemic carfentanil analog.<smiles>Nc1ccccn1</smiles>

60

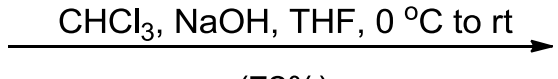

$(72 \%)$<smiles>CC(C)(C)OC(=O)N1CCC(Nc2ccccn2)(C(=O)O)CC1</smiles>

62

Scheme 16. Representative preparation of a hindered $\alpha$-amino acid (62) by way of a Bargellini reaction involving an amino heterocycles $(\mathbf{6 0})$.

The trichloromethide involved in the Bargellini reaction is typically generated by deprotonation of chloroform with sodium hydroxide. However, use of $\mathrm{NaOH}$ can compromise yields with substrates that are particularly prone to hydrolysis. Rohman and Myrboh recently reported that solid potassium fluoride coated with alumina $\left(\mathrm{KF} / \mathrm{Al}_{2} \mathrm{O}_{3}\right)$ serves as a viable replacement for sodium or potassium hydroxide in Bargellini condensation reactions (Scheme 17). ${ }^{34}$ Notably, under these conditions the reaction was highly successful in toluene but not in ethyl alcohol. The authors evaluated Bargellini reactions using substituted phenols, thiophenols, anilines, or 2-aminopyridine (63) as the nucleophile involved in substitution with the intermediate gem-dichloroepoxide and cyclohexanone or Boc-protected piperidine-4-one (64) as the initial carbonyl component. Yields of products 65 ranged from 56-91\% and are comparable to those reported in reactions conducted with hydroxide as the base.

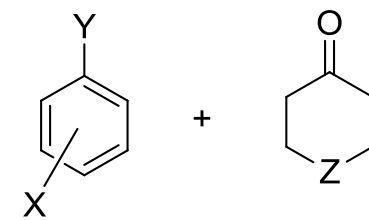

63

64

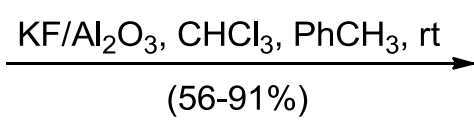

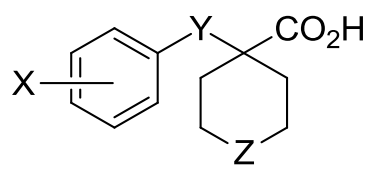

65

$\mathrm{Y}=\mathrm{OH}, \mathrm{SH}, \mathrm{NH}_{2}$

$\mathrm{Z}=\mathrm{CH}_{2}$, NBoc

$\mathrm{Y}=\mathrm{O}, \mathrm{S}, \mathrm{NH}$

$\mathrm{Z}=\mathrm{CH}_{2}, \mathrm{NBOC}$

Scheme 17. Alternative to hydroxide or DBU as base in Bargellini reactions

$\mathrm{Yu}$ and coworkers disclosed that $\alpha$-hydroxy acids could be prepared by treating simple ketones or aldehydes, including enolizable aldehydes, with sodium trichloroacetate and catalytic tetrabutylammonium bromide in chloroform/water using $70 \mathrm{~W}$ microwave irradiation (Scheme 
18). After trichloromethylation was judged complete (5-10 minutes), excess sodium hydroxide was added to the reaction mixture, and $\alpha$-hydroxy acid (67) formation was promoted by further irradiation at $100 \mathrm{~W}$ for 30-40 minutes. ${ }^{35}$ This expedient protocol offered promising yields (50$80 \%$ ) for nine tested substrates, but cinnamaldehyde displayed disappointing results. The method appears to be compatible with many aldehydes, and it obviates the traditional isolation of secondary trichloromethyl carbinols. Hence, the approach is a microwave-assisted hybrid of the Bargellini and Jocic-Reeve reactions.

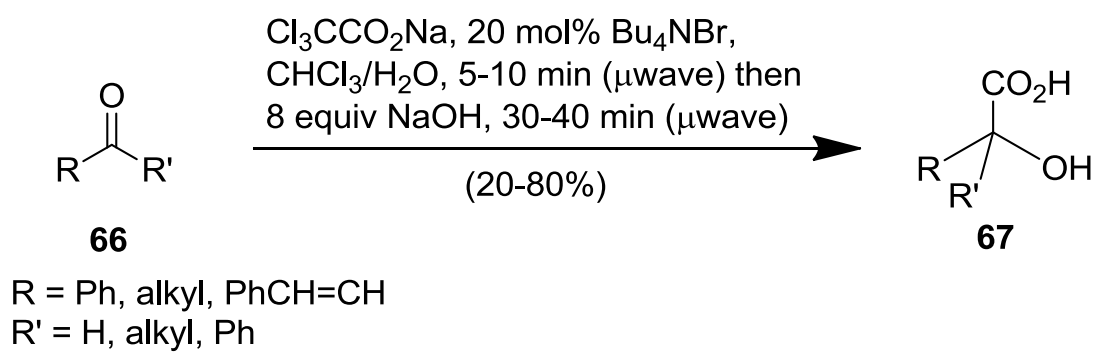

Scheme 18. One-pot microwave-promoted synthesis of 2-hydroxycarboxylic acids (67) from aldehydes or ketones.

\section{Conclusions}

Diverse 2-substituted acids, esters, amides, and heterocycles are readily accessible by way of reactions involving gem-dichloroepoxide intermediates. Jocic-Reeve, Corey-Link, and Bargellini reactions are likely to gain increasing exposure as powerful tools in synthesis based upon the array of products attainable through these methods and the efficiency and operational simplicity of the associated protocols. During the past decade, great strides have been made in clarifying the scope and limitations of these named reactions and in tailoring the conditions to create stepeconomical methods for the synthesis of targets important to industry, medicine, and biology. It is exciting to ponder what the next decade of advances in reactions involving gemdichloroepoxide intermediates might reveal.

\section{Acknowledgements}

We are grateful to the National Science Foundation CAREER program (CHE-0847686) and the American Chemical Society Petroleum Research Fund (44401-G1) for support of our work involving gem-dichloroepoxide intermediates.

\section{References}

1. Jocic, Z. Zh. Russ. Fiz. Khim. Ova. 1897, 29, 97. 
2. (a) Corey, E. J.; Link, J. O.; Shao, Y. Tetrahedron Lett. 1992, 33, 3435. (b) Corey, E. J.; Link, J. O. Tetrahedron Lett. 1992, 33, 3431. (c) Corey, E. J.; Link, J. O. J. Am. Chem. Soc. 1992, 114, 1906.

3. (a) Link, G. German Patent 80,986 (July 14, 1894) from: Chem. Zentr. 1895, 66(II), 70. (b) Bargellini, G. Gazz. Chim. Ital. 1906, 36, 329.

4. (a) To our knowledge, the first instance of an intermolecular substitution reaction involving a gem-dichloroepoxide intermediate being classified as a Jocic reaction was from: Oliver, J. E.; Schmidt, W. F. Tetrahedron: Asymmetry 1998, 9, 1723. Reeve also referred to a Jocic reaction, in a more restrictive sense, in reference 2 of: Reeve, W.; McKee, J. R.; Brown, R.; Lakshmanan, S.; McKee, G. A. Can. J. Chem. 1980, 58, 485. An earlier reaction reported as a Jocic reaction did not involve a gem-dichloroepoxide intermediate or relate to the chemistry described herein: Kibina, I. Y.; Shchelkunov, A. V.; Martynov, V. F. Trudy KhimikoMetallurgicheskogo Instituta, Akademiya Nauk Kazakhskoi SSR 1972, 18, 17. (b) To our knowledge, the first instance of a reaction involving a gem-dichloroepoxide intermediate being classified as a Corey-Link reaction was from: Dominguez, C.; Ezquerra, J.; Baker, S. R.; Borrelly, S.; Prieto, L.; Espada, C. M.; Pedregal, C. Tetrahedron Lett. 1998, 39, 9305. (c) To our knowledge, the first instance of a reaction involving a gem-dichloroepoxide intermediate being classified as a Bargellini reaction was from: Rychnovsky, S. D.; Beauchamp, T.; Vaidyanathan, R.; Kwan, T. J. Org. Chem. 1998, 63, 6363.”

5. (a) Reeve, W. Synthesis 1971, 131. (b) Reeve, W.; Bianchi, R. J.; McKee, J. R. A J. Org. Chem. 1975, 40, 339. (c) Reeve, W.; McKee, J. R.; Brown, R.; Lakshmanan, S.; McKee, G. A. Can. J. Chem. 1980, 58, 485. (d) Reeve, W.; Steckel, T. F. Can. J. Chem. 1980, 58, 2784.

6. For two excellent reviews concerning preparations and reactions of trichloromethyl carbinols, see: (a) Gukasyan, A. O.; Galstyan, L. K.; Avetisyan, A. A. Russ. Chem. Rev. 1991, 60, 1318. (b) Menezes, F. G.; Gallardo, H.; Zucco, C. Quim. Nova 2010, 33, 2233.

7. Snowden, T. S. The University of Alabama, Tuscaloosa, AL. Unpublished observations, 2005-2011. Also see: Nilsson, H.; Smith, L. Z. Physik. Chem. 1933, 166A, 136.

8. (a) Reeve, W.; Wood, C. W. J. Am. Chem. Soc. 1960, 82, 4062. (b) Reeve, W.; Compere, E. L., Jr. J. Am. Chem. Soc. 1961, 83, 2755. (c) Reeve, W.; Mutchler, J. P.; Liotta, C. L. Can. J. Chem. 1966, 44, 575. (d) Reeve, W.; Nees, M. J. Am. Chem. Soc. 1967, 89, 647. (e) Reeve, W.; Hoffsommer, J. C.; Auotto, P. F. Can. J. Chem. 1968, 46, 2233. (f) Reeve, W.; Barron, E. R. J. Org. Chem. 1975, 40, 1917. (g) Kiehlmann, E.; Wells, J. I.; Reeve, W. Can. J. Chem. 1976, 54, 1998. (h) Reeve, W.; Coley, W. R., III Can. J. Chem. 1979, 57, 444. (i) Reeve, W.; Tsuk, R. J. Org. Chem. 1980, 45, 5214.

9. Reeve, W.; Fine, L. W. J. Org. Chem. 1964, 29, 1148.

10. Blanchet, J.; Zhu, J. Tetrahedron Lett. 2004, 45, 4449.

11. Scaffidi, A.; Skelton, B. W.; Stick, R. V.; White, A. H. Aust. J. Chem. 2006, 59, 426. 
12. (a) Oliver, J. E.; Waters, R. M.; Lusby, W. R. Synthesis 1994, 273. (b) Khrimian, A. P.; Oliver, J. E.; Waters, R. M.; Panicker, S.; Nicholson, J. M.; Klun, J. A. Tetrahedron: Asymmetry 1996, 7, 37.

13. Morimoto, H.; Wiedemann, S. H.; Yamaguchi, A.; Harada, S.; Chen, Z.; Matsunaga, S.; Shibasaki, M. Angew. Chem. Int. Ed. 2006, 45, 3146.

14. Shamshina, J. L.; Snowden, T. S. Org. Lett. 2006, 8, 5881.

15. Sharpless, K. B.; Lauer, R. F. J. Am. Chem. Soc. 1973, 95, 2697.

16. Cafiero, L. R.; Snowden, T. S. Org. Lett. 2008, 10, 3853.

17. Gupta, M. K; Snowden, T. S. Manuscript in preparation.

18. Gupta, M. K; Li, Z.; Snowden, T. S. Manuscript in preparation.

19. Mellin-Morlière, C.; Aitken, D. J.; Bull, S. D.; Davies, S. G.; Husson, H. -P. Tetrahedron: Asymmetry 2001, 12, 149.

20. (a) Tennyson, R.; Romo, D. J. Org. Chem. 2000, 65, 7248. (b) Tennyson, R. L.; Cortez, G. S.; Galicia, H. J.; Kreiman, C. R.; Thompson, C. M.; Romo, D. Org. Lett. 2002, 4, 533. (c) Mitchell, T. A.; Romo, D. Heterocycles 2005, 66, 627.

21. Sorensen, M. H.; Nielsen, C.; Nielsen, P. J. Org. Chem. 2001, 66, 4878.

22. (a) Scaffidi, A.; Skelton, B. W.; Stick, R. V.; White, A. H. Aust. J. Chem. 2004, 57, 723. (b) Forman, G. S.; Scaffidi, A.; Stick, R. V. Aust. J. Chem. 2004, 57, 25.

23. Scaffidi, A.; Skelton, B. W.; Stick, R. V.; White, A. H. Aust. J. Chem. 2004, 57, 733.

24. Pedregal, C.; Prowse, W. Bioorg. Med. Chem. 2002, 10, 433.

25. (a) Habay, S. A.; Schafmeister, C. E. Org. Lett. 2004, 6, 3369. (b) Gupta, S.; Schafmeister, C. E. J. Org. Chem. 2009, 74, 3652.

26. Liu, G.; Romo, D. Org. Lett. 2009, 11, 1143.

27. For example, see: (a) Lai, J. T. J. Org. Chem. 1980, 45, 3671. (b) Lai, J. T. J. Org. Chem. 1981, 45, 754. (c) Lai, J. T. Synthesis 1981, 41. (d) Lai, J. T. Synthesis 1984, 124.

28. Lai, J. T. Tetrahedron Lett. 2001, 42, 557.

29. Youseff, A. M.; Safo, M. K.; Danso-Danquah, R.; Joshi, G. S.; Kister, J.; Marden, M. C.; Abraham, D. J. J. Med. Chem. 2002, 45, 1184.

30. Davis, R. D.; Fitzgerald, R. N.; Guo, J. Synthesis 2004, 12, 1959.

31. Cvetovich, R. J.; Chung, J. Y. L.; Kress, M. H.; Amato, J. S.; Matty, L.; Weingarten, M. D.; Tsay, F.-R.; Li, Z.; Zhou, G. J. Org. Chem. 2005, 70, 8560.

32. (a) Sen, P. K.; Biswas, B.; Venkateswaran, R. V. Tetrahedron Lett. 2005, 46, 8741. (b) Biswas, B.; Sen, P. K.; Venkateswaran, R. V. Tetrahedron Lett. 2006, 47, 4019. (c) Ghosh, S.; Tuhina, K.; Bhowmik, D. R.; Venkateswaran, R. V. Tetrahedron 2007, 63, 644. (d) Biswas, B.; Sen, P. K.; Venkateswaran, R. V. Tetrahedron 2007, 63, 12026.

33. Butcher, K. J.; Hurst, J. Tetrahedron Lett. 2009, 50, 2497.

34. Rohman, R.; Myrboh, B. Tetrahedron Lett. 2010, 51, 4772.

35. Yu, H.; Fang, Y.; Xia, Y.; Wu, J. Synth. Commun. 2006, 36, 2421. 